\title{
Using Dynamic Geometry Software to Enhance Specialized Content Knowledge: Pre-Service Mathematics Teachers' Perceptions
}

\author{
Ruti Segal ${ }^{1,2}(\mathbb{D})$, Victor Oxman ${ }^{1,3^{*}}$ (D), Moshe Stupel ${ }^{1,4}$ (D)
}

\author{
${ }^{1}$ Sha'anan College, Haifa, ISRAEL \\ ${ }^{2}$ Oranim College, Kiryat Tivon, ISRAEL \\ ${ }^{3}$ Western Galilee College, Acre, ISRAEL \\ ${ }^{4}$ Gordon College, Haifa, ISRAEL \\ *Corresponding Author: victor.oxman@gmail.com
}

Citation: Segal, R., Oxman, V., \& Stupel, M. (2021). Using Dynamic Geometry Software to Enhance Specialized Content Knowledge: Pre-Service Mathematics Teachers' Perceptions. International Electronic Journal of Mathematics Education, 16(3), em0647. https://doi.org/10.29333/iejme/11065

\section{ARTICLE INFO}

Received: 9 Mar. 2021

Accepted: 2 May 2021

\begin{abstract}
The study aimed to expose how pre-service teachers perceived the value of an inquiry-based geometrical task with dynamic geometry software for increasing and deepening their understanding of the task itself, and for heightening their mathematical, pedagogical, and technological knowledge in the case of reflection and transformation. Twenty-seven pre-service teachers studying to become middle-school (junior high) mathematics teachers were assigned an inquiry-based geometrical task to explore - both by conventional, low-tech means (paper and pencil) and then in a dynamic geometry software (DGS) environment - the properties of objects formed by reflections in polygons (triangles and quadrilaterals) and to offer conjectures and proofs regarding the final polygon's shape and area concerning the original. The results show that the majority of participants indicated that DGS provided a valuable instrument for revising and expanding their knowledge, that the assignment demonstrated the value that technological tools have in teaching and learning processes, and the importance of adapting learning tasks in geometry to a dynamic geometry environment for expanding and deepening geometrical and pedagogical knowledge and reasoning skills.
\end{abstract}

Keywords: inquiry-based geometric task, reflection, dynamic geometric sofrware, specialized content knowledge, technological pedagogical and mathematical knowledge for teaching

\section{INTRODUCTION}

\section{Mathematics Teachers' Knowledge}

Over the past few decades, scholars in the field of mathematics education have been surveying and characterizing the type of knowledge that is essential for mathematics teachers.

Relying on Shulman's (1986) work, which suggests that teachers require unique types of knowledge and that defined two key concepts to describe them - subject matter knowledge and pedagogical content knowledge - Ball and Bass (2003) tried to characterize the knowledge required for mathematics teachers. By observing teachers in the classroom and focusing on the tasks offered and the mathematical knowledge required to manage these tasks, they determined that the knowledge required of mathematics teachers is even more unique. They thus defined the concept of "mathematical knowledge for teaching" (MKT). MKT spans all areas and levels of school mathematics; supports the teacher's interrelated concepts and highlights their integrative nature, and allows evaluation of which mathematical tasks are worthy of inclusion in teaching and how to incorporate and manage them.

Ball, Thames, and Phelps (2008) later expanded this research and refined the term MKT to define six sub-domains: three under subject matter knowledge and three under pedagogical content knowledge. ${ }^{1}$ One of these sub-domains, "specialized content knowledge" (SCK), is relevant to this study. This is the knowledge required from those involved in mathematics education about how to present mathematical ideas, intelligently juxtapose examples, link different representations of a given concept, and more. In the present study, we will focus on the contribution that inquiry-based geometric tasks integrating dynamic geometry software

\footnotetext{
${ }^{1}$ The six subdomains are as follows: common content knowledge (CCK), horizon content knowledge (HCK), and specialized content knowledge (SCK) are related to SMK; knowledge of content and students (KCS), knowledge of content and teaching (KCT), and knowledge of content and curriculum (KCC) are a part of PCK (Ball, Thames, \& Phelps 2008).
} 
makes to pre-service SCK as it relates to learning and teaching geometrical content involving reflection and transformation processes.

There is a close relationship between mathematical knowledge for teaching (MKT) in all its components and the quality of mathematical instruction. A teacher with broad, deep MKT will present the learners with a mathematical richness that will be reflected by the number of representations and examples beyond what is offered in the classroom textbook, will be thoroughly familiar with the curriculum and ways to link the various subjects of study, and, also, will use the sources available knowledgeably and correctly during teaching (Hill et al., 2008; Ma, 1999).

\section{Teachers' Technological and Pedagogical Content Knowledge}

Koehler and Mishra $(2006,2009)$ also based their research on the types of knowledge defined by Shulman (1986) and coined the term "Technological, Pedagogical, and Content Knowledge" (TPACK), which is an amalgamation of technological knowledge (TK), pedagogical knowledge (PK), and content knowledge (CK). Specifically, TK is knowledge about the various technologies available for teaching in the classroom environment, PK is knowledge about methods and instruction processes, and CK is knowledge of the topics relevant to learning or teaching (i.e., the content the teachers are supposed to teach, which varies according to the different topics). TPACK implies that all these bodies of knowledge intersect at various levels of complexity. TPACK has become a useful framework to describe and understand the goals involved in integrating technology into teacher education because it encompasses the knowledge teachers require to effectively integrate technology during their teaching (Schmidt et al., 2009). The model's complexity is reflected in the common components of basic knowledge. For example, TCK technological content knowledge - is knowledge about how technology can create different representations for a specific concept; it demands that the teacher understands how using specific technologies can affect learners' skills and understanding of the relevant concepts and content. TPK- technological pedagogical knowledge - is familiarity with the range of technologies that can be integrated into teaching and understanding how their use can affect teaching methods. Thus, TPACK encompasses the intersection of the basic types of knowledge that teachers require to integrate technologies into their teaching no matter what the content area. It includes an understanding of the representation of concepts using technology; pedagogical techniques that use technologies in constructive ways to teach content; knowledge about what makes concepts difficult or easy to learn; appreciation of how technology can help students solve tasks; and knowledge of how technology can be used to develop new knowledge based on existing knowledge.

The above formed the framework for the present study, which was to investigate the perceptions pre-service mathematics teachers have about the development of their technological content knowledge and technological pedagogical knowledge during their coping with inquiry-geometrical task.

The impact of digital technology on education in the 21st century calls on teachers to prepare for more dynamic teaching, that is to say, the use of digital-based communication platforms and collaborative work to enhance students' critical and creative thinking and accelerate the learning processes. This, to prepare students for the challenges of life in a technological society (Niess \& Gillow-Wiles, 2017). Thus, an important - even essential - task for teacher educators is to ensure that teachers know how to utilize technology as a tool for teaching and learning. Teachers must become empowered professionals able to design technological environments for learning and teaching and evaluate classroom environments that are based on and driven by technologies (Angeli \& Valanides, 2009; Niess, 2005).

\section{Integrating Inquiry-based Geometrical Tasks into the Dynamic Geometry Environment}

Another shift in mathematics instruction - geometry in particular - in recent decades is the inclusion of inquiry-based activities into the lessons to provide meaningful learning opportunities for students (Da Ponte, 2007; Leikin, 2004). Incorporating inquirybased tasks into geometry instruction almost inherently encourages the use of a dynamic geometry software (DGS) environment (Hölzl, 2001; Mariotti, 2002; Yerushalmy \& Chazan, 1993). DGS provides convenient and often fascinating learning opportunities for investigating geometric properties and deepening understanding (De Villiers, 1998; Leikin, 2012; Leung \& Lopez-Real, 2002; Oxman, Stupel, \& Segal, 2016; Segal, Oxman, \& Stupel, 2015; Stupel, Sigler, \& Oxman, 2017). DGS gives learners a dynamic view of geometrical objects and an opportunity to explore and speculate about their properties, relationships, generalizations, and more. Observing what occurs when geometric objects are "dragged" in a DGS environment allows students to compare a variety of examples of a given, non-variable conjecture (Leung \& Lopez-Real, 2002). Stupel and Ben-Chaim (2013) termed the process of making conjectures and identifying non-variable conjectures "semi-proof."

Nevertheless, teachers must also be aware that using DGS may reduce the gap between experiment and theory in the acquisition and justification of geometric knowledge, which is an important pedagogical and epistemological concern (De Villiers, 2004). Simply observing a (large) variety of representations displayed on the screen does not equal formal mathematical proof; it is simply a virtual experiment leading to the hypotheses that needs to be proved. Nevertheless, investigative methods in a nondeductive DGS environment that rely on inductive experimentation and intuition do seem to provide a more significant context for learning geometry than the traditional proof-of-evidence approach (Leung \& Lopez-Real, 2002).

For the reasons noted above, it is important to integrate instruction about presenting inquiry-based tasks in a DGS environment as part of teacher training courses. This, to arouse pre-service teachers' awareness of how the integration and adaptation of DGS and similar activities is a valuable part of teaching (Da Ponte \& Henriques, 2013; Ellerton, 2013).

\section{The Inquiry-based Activity: A Reflection of a Point in a Polygon through the Midpoints of its Sides}

For the inquiry-based assignment used in this study, students were given several polygons (triangles and squares) and asked to determine what type of polygon results from the reflection of a random point (internal to the polygon on one of its sides 


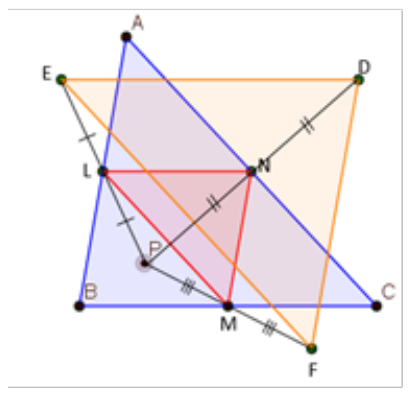

(a)

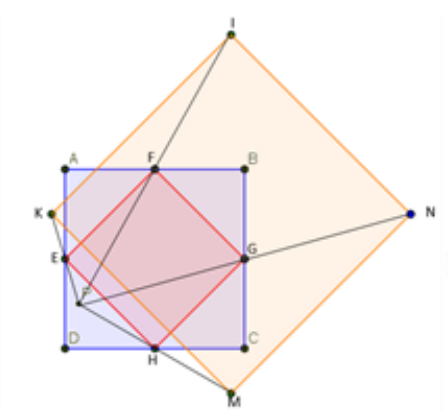

(b)

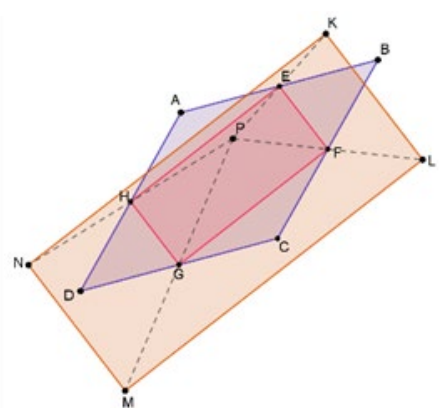

(c)

Figure 1. Diagrams to illustrate reflected-polygon assignment demonstrated by the applets

[including vertices], or external to it) through the midpoints of the given polygon's sides. They were then asked to compare the original and reflected polygons: what properties were retained and which were not, whether the original polygon's shape was preserved, and whether the ratios of their sides and the ratio of their areas changed.

For Part I, students were asked to explore the task using the traditional method to construct the reflected polygon, formulate some initial conjectures about the shape of the reflected polygon, and the ratio between the sides and areas of the original and reflected polygons, and prove them using deductive tools. In Part II, students were to examine their conjectures and conclusions from Part I using applets (developed by GeoGebra DGS) developed specifically for each shape. Students were then asked to correct, modify, and expand their answers from Part I based on their work in the DGS environment.

An additional DGS applet with a drag bar that allowed changing the number of sides of the polygon from 3 to 10 was prepared to give an overview of this concept. It allowed dragging vertices or sides to change the shapes, lengths, and positions of sides and angles; and the ability to change the location of the reflection point. Throughout the manipulations, the ratio between the areas of the reflected and original polygons was displayed on-screen. This DGS applet can be accessed via the following link: https://www.GeoGebra.org/m/n5v5faj9.

\section{Three Examples of the Reflected-Polygon Assignment Demonstrated by the Applets}

\section{Given: Triangle (See Figure 1a)}

Triangle $A B C$ may be any triangle. The midpoints of its sides are $L, M$, and $N$.

A point, $P$, is selected within triangle $A B C$ and reflected through the midpoints of the sides of $A B C$ to obtain points $D, E$, and $F$, which form the vertices of the reflected triangle.

\section{Given: Square (See Figure 1b)}

Quadrilateral $A B C D$ is a square. The midpoints of its sides are $E, F, G$, and $H$.

A point, $P$, is selected within square $A B C D$ and reflected through the midpoints of the sides of $A B C D$ to obtain points $K, I, N$, and $M$, which form the vertices of the reflected quadrilateral.

\section{Given: Rhombus (See Figure 1c)}

Quadrilateral $A B C D$ is a rhombus. The midpoints of its sides are $E, F, G$, and $H$.

A point, $P$, is selected within rhombus $A B C D$ and reflected through the midpoints of the sides of $A B C D$ to obtain points $K, L, M$, and $\mathrm{N}$, which form the vertices of the reflected quadrilateral.

\section{METHODOLOGY}

\section{Research Question}

What contribution does solving a geometric inquiry-based activity within a DGS environment make to pre-service middle school mathematics teachers' mathematical, pedagogical, and technological knowledge?

\section{Participants}

Twenty-seven pre-service teachers studying towards a B.Ed. in middle school (junior high) mathematics education in an academic teachers' college in Israel participated. The training program for mathematics teachers for teaching mathematics in middle school and high school includes mathematics courses that deal with diverse and advanced mathematical content, didactics courses that include various pedagogical approaches for teaching mathematics, familiarity with The Curriculum for Teaching Mathematics on behalf of the Supervision of Mathematics Teaching at the Ministry of Education, and courses involving technologies such as a massive open online course on geometric constructions with a ruler and compass in a dynamic geometry environment, learning and teaching geometry, and calculus integrated with various mathematical software such as GeoGebra, Desmos, and etc. The present study was conducted during students participating in the "Teaching Geometry with Technology" course. 
Table 1. Number of students who presented correct conjectures and deductive proofs in traditional and DGS environments $(n=$ 27)

\begin{tabular}{|c|c|c|c|c|c|}
\hline \multirow{3}{*}{ Inquiry about } & \multirow{3}{*}{ Original polygon } & \multicolumn{4}{|c|}{ Number of students $(\%)(n=27)$} \\
\hline & & \multicolumn{2}{|c|}{ Correct conjecture } & \multicolumn{2}{|c|}{ Correct proof } \\
\hline & & Using a pencil and ruler & Also using GeoGebra & Using a pencil and ruler & Also using GeoGebra \\
\hline \multirow{6}{*}{$\begin{array}{l}\text { Type of } \\
\text { Reflected } \\
\text { polygon }\end{array}$} & Triangle & $18(67 \%)$ & $27(100 \%)$ & $12(45 \%)$ & $23(86 \%)$ \\
\hline & Square & $17(63 \%)$ & $27(100 \%)$ & $11(41 \%)$ & $23(86 \%)$ \\
\hline & Rectangle & $15(55 \%)$ & $26(96 \%)$ & $10(37 \%)$ & $20(74 \%)$ \\
\hline & Rhombus & $15(55 \%)$ & $26(96 \%)$ & $10(37 \%)$ & $20(74 \%)$ \\
\hline & Trapezoid & $15(55 \%)$ & $26(96 \%)$ & $10(37 \%)$ & $20(74 \%)$ \\
\hline & General quadrilateral & $15(55 \%)$ & $26(96 \%)$ & $10(37 \%)$ & $20(74 \%)$ \\
\hline \multirow{6}{*}{ Ratio of areas } & Triangle & $18(67 \%)$ & $27(100 \%)$ & $15(55 \%)$ & $24(88 \%)$ \\
\hline & Square & $17(63 \%)$ & $27(100 \%)$ & $16(59 \%)$ & $25(92 \%)$ \\
\hline & Rectangle & $13(48 \%)$ & $27(100 \%)$ & $9(33 \%)$ & $14(51 \%)$ \\
\hline & Rhombus & $13(48 \%)$ & $27(100 \%)$ & $9(33 \%)$ & $14(51 \%)$ \\
\hline & Trapezoid & $13(48 \%)$ & $27(100 \%)$ & $9(33 \%)$ & $14(51 \%)$ \\
\hline & General quadrilateral & $13(48 \%)$ & $27(100 \%)$ & $9(33 \%)$ & $14(51 \%)$ \\
\hline
\end{tabular}

\section{Research Process}

The study was conducted as part of the year-long "Teaching Geometry with Technology" course. In the present framework, we focused on two examples of an inquiry-based geometry assignment submitted to students during their course.

Part I: In pairs, students were asked to investigate the assigned tasks using paper, pencil, and ruler; to offer conjectures about what type of polygons would be obtained from the reflection process, and to justify their conjectures.

Part II: The students were to continue their investigation of the tasks in Part I more thoroughly using GeoGebra DGS and formulate more accurate conjectures.

Part III: Students completed a questionnaire summarizing their learning process in both environments.

Part IV: Semi-structured individual interviews were conducted with seven students (selected to reflect the heterogeneous capabilities of the students as a group).

\section{Research Tools}

1. The completed (submitted via the course's website) inquiry-based assignments for Parts I and II.

2. Recordings of student discussions during Parts I and II.

3. A student questionnaire that was based on one developed by Schmidt and colleagues (2009) and included nine closed statements (rated on a 1-5 Likert scale) and five open-ended questions about various aspects of the contributions that DGS used during the inquiry-based geometry assignment made to their mathematical, pedagogical and technological knowledge.

4. Notes prepared by this researcher during the semi-structured interviews with the seven students. The purpose of the interviews was to evaluate and understand the implications of the student worksheets, discussions, and questionnaires, and to more fully understand the contribution of the technology to the students' mathematical, pedagogical, and technological knowledge.

\section{Data Analysis}

The study was conducted according to a qualitative research paradigm that employs open and axial coding processes to identify main and subcategories (Corbin \& Strauss, 2008). In the first stage of analysis, primary categories were identified and mapped by first analyzing student responses to the tasks in both traditional and DGS environments and correlating them to the data from the questionnaires. In the second phase, we analyzed and correlated the data from participants' comments and feedback, classroom discussions, and interviews, based on the methods described by Miles and Huberman (1994) for integrating and validating qualitative findings. In the third phase, we reviewed the first- and second-stage findings with a focus on data about the development of the pre-service teachers' mathematical, pedagogical, and technological knowledge.

\section{FINDINGS}

\section{Geometrical-Task Inquiry based on Paper-Pencil-Ruler (Traditional) and GeoGebra Dynamic Environments}

Table 1 shows how many students offered both correct conjectures regarding the shape of the reflected polygons and the ratio of the areas of the original and reflected polygons and a proper deductive proof in each environment (traditional and DGS). Note: Because the number of students who gave correct answers and conjunctures for the rectangle, rhombus, trapezoid, and general quadrilateral were very similar, for simplicity's sake we used the average value for all four. 


\section{Conjectures Made in the Traditional (Paper-Pencil-Ruler) Environment}

Table 1 shows that in the traditional environment, a minimum of 15 out of the 27 students $(>55 \%)$ were able to make correct conjectures about the reflected polygons and at least $13(>48 \%)$ about the ratio of the areas between the original and reflected polygons. However, the worksheets showed that even though students might have offered a correct conjecture, their proofs were often incorrect because they relied on manual sketches to identify the shape of the reflected polygon and predicted the area ratios based on visual reckoning and not on precise calculations using the sides and angles. (The students who did offer the correct conjecture performed the proper calculations.)

The student's reasoning indicated that students were uncertain about their conjectures especially when the shape of the reflected polygon was not the same as the original: "I saw that the polygon reflected from the rectangle was not as observed in the case of the squares"; "I was unable to determine if it was a parallelogram, rhombus, or kite. Therefore, l'm not sure about my conjecture that it is rhombus"; "I presumed that the ratio of the areas between the rhombus (original quadrilateral) and the rectangle (reflected quadrilateral) would be 2:1, that is, the same as what I had in the case of the squares."

Also, the students' reasoning showed that, among other things, an incorrect conjecture was generally the result of a lack of geometric knowledge. For example, they were not sure about the sufficient conditions for determining if a given square is a parallelogram "I think the reflected quadrilateral of the rectangle will be a parallelogram because the opposite angles are equal"), or they incorrectly constructed the reflected polygon because they did not know how to correctly perform a reflection ("I positioned the reflection point by constructing a vertical to the side of the rectangle and extending it along its length"), or they put too much reliance on their partner's incorrect answer ("I obtained a square when the original polygon was a square. But my partner did not, so we decided to say that the reflected quadrilateral of the square is a quadrilateral; this covered both our results").

Students who did not present any conjecture at all seemed to do this as a result of their insecurity in formulating a conjecture based on their drawings or could not see any connection between the original and reflected polygons: "The reflection of the triangle yielded a triangle, but we could not agree on which type of triangle"; "We could not verify a relationship between the area of the original square and the reflected quadrilateral based on the cases we drew."

\section{Conjectures Made in the DGS (GeoGebra) Environment}

As can be immediately observed from Table 1, working in the DGS environment allowed students - including those who had not previously experienced success - to offer correct conjectures. It allowed students to observe an accurate reflection process and made them more confident of what they were observing: "With the applets, we immediately realized our error in constructing the reflected polygon: we had constructed the reflection from the side of the original polygon but not at the midpoint of the side." The GeoGebra environment also allowed students to observe a wide range of polygons reflecting from the original polygon. Some example statements: "Working with the applet made it quicker and more accurate to identify the type of reflected quadrilateral. We could drag the reflection point inside the rectangle and see that the result was always a rhombus because the sides remained equal"; "With the applets, I felt more confident offering the conjecture that the reflected quadrilateral was a rhombus: no matter the point's location, I could drag the reflected quadrilateral's vertices and see that there were always four right angles"; "With the applets, I realized my previous conjecture (reflected quadrilateral of a rectangle is a parallelogram) was inaccurate. Now I could see it was a rhombus: not only were opposite angles equal, but all sides were of equal length."

\section{Deductive Proofs in both Environments}

The data in Table 1 show that of the students who offered correct conjectures in the traditional environment, approximately $66 \%$ gave a correct deductive proof about the type of reflected polygon and around $80 \%(67 / 87)$ for the ratio of areas. These included a structured investigative process ranging from specific cases to a generalization.

Table 1 also shows the increase in the number of students who were able to present correct deductive proof following the transition to the DGS environment. Explanations acquired during the interviews include the following: "When working with the GeoGebra applets, I could see that the reflected polygon of a trapezoid was a parallelogram. This led me to think about the definition of a parallelogram and helped me focus on what I had to prove"; "While working with the applets, I measured angles, segments and sides. While dragging the vertices, I observed a wide variety of reflected polygons and observed some common features in all of them. This led me to construct my proof."

\section{Findings from the Concluding Questionnaire}

Table 2 presents the rating distribution for four out of the nine closed statements in the questionnaire.

Table 2 indicates that about 55\% of the pre-service teachers agree or strongly agree that the inquiry-based activity gave them the required skills to use GeoGebra software in the geometry teaching classroom environment, with about $37 \%$ agreeing moderately. In their explanations, they referred both to skills needed for using ready-made, specially built applets ("I learned how to use the prepared applet that allows calculating such things as area, and measuring lengths and angles"), and skills for finding other GeoGebra applets in the digital media: "Working with the applets helped me during the inquiry process, and this inspired me to search for other ready-made applets in other sites. I found some applets on the Math Teachers Center website and also on the GeoGebra site that I intend to incorporate into teaching."

Besides, the majority of students (85\%) who responded to the questionnaire felt that the experience had expanded their technological pedagogical knowledge. This was expressed by their intentions to integrate inquiry-based activities with GeoGebra software to a "great" or "very great" extent to accelerate the learning processes of their students. This was reinforced during their interviews: "I want to share my experience of working on the inquiry task with a given applet with my students because if it helped me, then I am sure it will benefit them too"; "From my experience of inquiry-based activity with the applets, I think that incorporating 
Table 2. Distribution of students' degree of agreement with four statements: (numbers indicate the number of students out of 27 who gave each score). (Based on Schmidt et al., 2009)

\begin{tabular}{|c|c|c|c|c|c|c|}
\hline & Statement & $\begin{array}{l}1 \text { (don't } \\
\text { agree) }\end{array}$ & 2 & 3 & 4 & $\begin{array}{l}5 \text { (fully } \\
\text { agree) }\end{array}$ \\
\hline 1 & $\begin{array}{l}\text { The inquiry activity accorded me the required skills to use GeoGebra software for } \\
\text { teaching geometry in the classroom environment (TK). }\end{array}$ & & 2 & 10 & 7 & 8 \\
\hline 2 & $\begin{array}{l}\text { I intend to include inquiry activities using GeoGebra software to enhance my students' } \\
\text { learning processes (TPK). }\end{array}$ & & & 4 & 10 & 13 \\
\hline 3 & I can adapt the GeoGebra software to construct different activities in geometry (TPK). & & & 5 & 14 & 8 \\
\hline 4 & $\begin{array}{l}\text { An inquiry activity using GeoGebra software may lead to expanding my students' } \\
\text { mathematical knowledge (TCK). }\end{array}$ & 2 & 1 & 8 & 9 & 7 \\
\hline
\end{tabular}

this into my classroom will make more students understand the assignment and all the concepts involved"; "I learned how to present an inquiry-based activity in a DGS environment using ready-made applets that allow students to experiment with a real inquiry." In addition, during the interviews, the students emphasised the importance of including inquiry activities using GeoGebra software for a better quality of learning when using interactive technology for expanding and deepening their students' mathematical knowledge: "During the inquiry geometric activity, I recognized that I could ask my students a different type of question appropriate to a technological environment, such as formulating a hypothesis from the collection of examples displayed on the screen by dragging polygons' points and sides, or trying to identify a constant ratio between side lengths or areas of different polygons." Also, 59\% of students reported that the inquiry-based activity in the DGS environment expanded their technological mathematical knowledge to a "great" or "very great" extent: "During the activity, I learned how to use the software to construct a reflection and to use this to expand my students' knowledge to differentiate between central symmetry and line symmetry"; "Using applets, I can promote knowledge about inclusion relationships in the family of quadrilaterals and their properties and definitions. For example, that the definition of a parallelogram includes the properties of a rhombus"; "From my experience with the inquiry activity in a technological environment, I recalled a wide variety of things that I had studied previously and forgotten, such as what are sufficient conditions for determining the type of quadrilateral and the distinction between the properties of a quadrilateral and its definition." In addition, the students deepened their mathematical inquiry by tracking the lengths of the sides of a wide range of quadrilaterals formed by connecting the midpoint of the original quadrilaterals and the sides of the reflection quadrilaterals, as well as their area ratio, and concluded: "I was surprised to see that as a result of the reflection process, the polygons formed by connecting the midpoints of the sides of the original quadrilaterals were expanded by a factor of 2, and that the ratio of the areas in all cases as a result of the expansion was 1:4"; "The GeoGebra environment encourages me to find the reasoning for relationships between the type of original quadrilaterals and reflected quadrilaterals, such as why, when the original quadrilateral was a square, the reflected quadrilateral is also a square, but when the original quadrilateral was a rhombus, the reflected quadrilateral is a rectangle."

Nevertheless, it is important to note that some of the explanations given by students who failed to present a conjecture and/or proof show that students had difficulties working in a technological environment: "I had a problem with the operation of some of the applets, so I was unable to finish the assignment"; "I didn't feel confident working in the GeoGebra environment because I felt I needed more experience to make use of this environment on my own before I integrate it into a classroom with my students." Other statements indicated an insufficient understanding of how to properly present deductive proof.

\section{DISCUSSION AND CONCLUSIONS}

The findings indicate that, for the most part, students perceived that conducting inquiry-based activities in the GeoGebra environment was a lever for developing and expanding their technological content knowledge, technological pedagogical knowledge, and their specialized content knowledge related to learning and teaching geometry task involving reflection and transformation as described below.

Technological Content Knowledge (TCK): Consistent with the definition of Schmidt and colleagues (2009), students perceived the activity expanded their technological-mathematical knowledge of how DGS allows the visualization of different representations of mathematical/geometrical concepts, led them to understand how the use of appropriate technology (e.g. GeoGebra) can improve their mathematical/geometrical knowledge and skills, and increased their understanding of the importance of formulating a conjecture based on a wide range of examples to provide a semi-proof (Stupel \& Ben-Chaim, 2013) on the way to formulating a complete deductive proof. The students also gained a dynamic view of geometrical objects and an opportunity to explore and speculate about their properties, relationships, and generalizations (Oxman, Stupel, \& Segal, 2016; Segal, Oxman, \& Stupel, 2015; Stupel, Sigler, \& Oxman, 2017).

In addition, the technological environment allowed some students to deepen their mathematical inquiry about possible mathematical relationships between original quadrilaterals and reflected quadrilaterals. For example, in the rich dynamic geometry environment (GeoGebra) some students realized that they can explore why when the original quadrilateral is a square the reflected quadrilateral is also a square, and why the shape preservation does not take place in the case where the original quadrilateral is a rhombus, where the reflected quadrilateral is a rectangle. The rich experience offered by DGS allowed students to identify reciprocal relationships between the diagonals of the original quadrilaterals and the midlines connecting two midpoints of adjacent sides of the original quadrilateral, and the reflected quadrilateral.

Technological Pedagogical Knowledge (TPK): Also following the definition provided by Schmidt and colleagues (2009), the students perceived that the activity expanded their technological pedagogical knowledge in the context of geometry instruction, 
especially regarding how DGS can be incorporated therein and how the use of applets or such can modify their teaching methods by offering students inquiry-based activities to encourage success and provide novel learning experiences. Also, the pre-service teachers perceived that the activity expanded their TPK in the context of how the integration of technology contributes to the experience of success in the transition from traditional (paper-pencil-ruler) inquiry-based tasks to using DGS. For example, in the GeoGebra environment, some students were able to identify how the technological environment allowed them to deal with their difficulties of formulating hypotheses in a paper and pencil environment based on limited examples, and how the transition to a dynamic geometric environment allowed them to be more active. Students expanded their TPC knowledge about the contribution of integration and assignment in a dynamic geometric environment to enable their students to be more active and to gain a more comprehensive understanding.

Specialized Content Knowledge (SCK): In line with Ball, Thames, and Phelps's definition (2008), the participants indicated that the inquiry-based DGS activity contributed to expanding their specialized content knowledge in the context of teaching geometry in a DGS environment: specifically, how to formulate, present, and manage geometry tasks involved with concepts, definition, and generalization, and to notice how such an environment can provide a wider, more comprehensive view of the properties, definitions, and characteristics of geometric shapes. For example, the students' experience with the given inquirybased geometric task showed them the contribution that integrating dynamic applets can make in allowing them to actively carry out an intriguing, in-depth exploration of the geometric concepts and be involved in the solution process. Also, the students became aware of how diverse inquiry tasks that are linked to various geometric concepts can be combined in one task.

Overall, the students' experience in the inquiry-based DGS activity increased their awareness of how mathematics teachers must combine unique knowledge with the intelligent management of geometric tasks and expanded their specialized technological-mathematical and specialized technological-pedagogical knowledge for the teaching of geometry.

\section{FOR FURTHER STUDY}

This present study was conducted in a limited framework of 27 pre-service teachers studying to become mathematics teachers for middle school (junior high) and the assigned task involved a reflection of a random point relative to the midpoint of the sides of a given polygon. This might be expanded to include a larger number of study participants, which would call for a combination of quantitative and qualitative research. Also, this study can be expanded to include tasks involving different points of reflection, different types of reflection problems, and different types of geometrical problems in the DGS environment. It would be enlightening to examine a similar task integration within other teacher-training frameworks for middle-school math teachers and compare the findings.

Finally, follow-up studies could focus more on students' understanding processes of concepts learned combined with dynamic geometric software, and compare the comprehension processes of students who have studied the same geometric concepts or geometric tasks without technology. These kinds of studies and their findings may assist mathematics teacher educators in constructing appropriate specialized courses that include different approaches and ways of teaching geometry integrated with technology.

Author contributions: All authors have sufficiently contributed to the study, and agreed with the results and conclusions.

Funding: No funding source is reported for this study.

Declaration of interest: No conflict of interest is declared by authors.

\section{REFERENCES}

Angeli, C., \& Valanides, N. (2009). Epistemological and methodological issues for the conceptualization, development, and assessment of ICT-TPCK: Advances in technological pedagogical content knowledge (TPCK). Computers \& Education, 52(1), 154-168. https://doi.org/10.1016/j.compedu.2008.07.006

Ball, D. L., \& Bass, H. (2003). Toward a practice-based theory of mathematical knowledge for teaching. In B. Davis \& E. Simmt (Eds.), Proceedings of the 2002 Annual Meeting of the Canadian Mathematics Education Study Group (pp. 3-14). CMESG/GCEDM.

Ball, D. L., Thames, M. H., \& Phelps, G. (2008) Content knowledge for teaching: What makes it special? Journal of Teacher Education, 59(5), 389-407. https://doi.org/10.1177/0022487108324554

Corbin, A., \& Strauss, J. (2008). Basics of qualitative research: Techniques and procedures for developing grounded theory (3rd edition). SAGE Publications. https://doi.org/10.4135/9781452230153

Da Ponte, J. P. (2007). Investigations and explorations in the mathematics classroom. ZDM: The International Journal on Mathematics Education, 39, 419-430. https://doi.org/10.1007/s11858-007-0054-z

Da Ponte, J. P., \& Henriques, A. C. (2013). Problem posing based on investigation activities by university students. Educational Studies in Mathematics, 83, 145-156. https://doi.org/10.1007/s10649-012-9443-5

De Villiers, M. (1998). An alternative approach to proof in dynamic geometry. In R. Lehrer \& D. Chazan (Eds.), Designing learning environments for developing understanding of geometry and space (pp. 369-394). Lawrence Erlbaum Associates.

De Villiers, M. (2004). The role and function of quasi-empirical methods in mathematics. Canadian Journal of Science, Mathematics and Technology Education, 4(3), 397-418. https://doi.org/10.1080/14926150409556621 
Ellerton, N. F. (2013). Engaging pre-service middle-school teacher-education students in mathematics problem posing: Development of an active learning framework. Educational Studies in Mathematics, 83, 87-101 https://doi.org/10.1007/s10649012-9449-z

Hill, H. C., Blunk, M. L., Charalambous, C. Y., Lewis, J. M., Phelps, G. C., Sleep, L., \& Ball, D. L. (2008). Mathematical knowledge for teaching and the mathematical quality of instruction: An exploratory study. Cognition and Instruction, 26(4), 430-511. https://doi.org/10.1080/07370000802177235

Hölzl, R. (2001). Using dynamic geometry software to add contrast to geometric situation-a case study. International Journal of Computers for Mathematical Learning, 6(1), 63-86. https://doi.org/10.1023/A:1011464425023

Koehler, M. J., \& Mishra, P. (2009). What is technological pedagogical content knowledge? Contemporary Issues in Technology and Teacher Education, 9(1), 60-70.

Leikin, R. (2004). Towards high quality geometrical tasks: Reformulation of a proof problem. In M. J. Hoines \& A. B. Fuglestad (Eds.), Proceedings of the 28th International Conference for the Psychology of Mathematics Education (Vol. 3, pp. 209-216). International Group for the Psychology in Mathematics Education.

Leikin, R. (2012). What is given in the problem? Looking through the lens of constructions and dragging in DGE. Mediterranean Journal for Research in Mathematics Education, 11(1-2), 103-116.

Leung, A., \& Lopez-Real, F. J. (2002). Theorem justification and acquisition in dynamic geometry: A case of proof by contradiction. International Journal of Computers for Mathematical Learning, 7(2), 145-165. https://doi.org/10.1023/A:1021195015288

Ma, L. (1999). Knowing and teaching elementary mathematics: Teacher's understanding of fundamental mathematics in China and the United States. Lawrence Erlbaum Associates. https://doi.org/10.4324/9781410602589

Mariotti, M. A. (2002). The influence of technological advances on students' mathematics learning. In L. D. English (Ed.), Handbook of international research in mathematics education (pp. 695-723). Erlbaum.

Miles, M. B., \& Huberman, A. M. (1994). Qualitative data analysis. SAGE Publications.

Mishra, P., \& Koehler, M. J. (2006). Technological pedagogical content knowledge: A framework for teacher knowledge. Teachers College Record, 108(6), 1017-1054. https://doi.org/10.1111/j.1467-9620.2006.00684.x

Niess, M. L. (2005). Preparing teachers to teach science and mathematics with technology: Developing a technology pedagogical content knowledge. Teaching and Teacher Education, 21(5), 509-523. https://doi.org/10.1016/j.tate.2005.03.006

Niess, M. L., \& Gillow-Wiles, H. (2017). Expanding teachers' technological pedagogical reasoning with a systems pedagogical approach. Australasian Journal of Educational Technology, 33(3). https://doi.org/10.14742/ajet.3473

Oxman, V., Stupel, M., \& Segal, R. (2016). On teaching extrema triangle problems using dynamic investigation. The International Journal of Mathematical Education in Science and Technology (UK), 48(4), 603-619. https://doi.org/10.1080/0020739X.2016.1259514

Schmidt, D. A., Baran, E., Thompson, A. D., Mishra, P., Koehler, M. J., \& Shin, T. S. (2009). Technological pedagogical content knowledge (TPACK): The development and validation of an assessment instrument for preservice teachers. Journal of Research on Technology in Education, 42(2), 123-149. https://doi.org/10.1080/15391523.2009.10782544

Segal, R., Oxman, V., \& Stupel, M. (2015). Dynamic investigation of loci with surprising outcomes and their mathematical explanations. The International Journal of Mathematical Education in Science and Technology (UK), 47(3), $443-462$. https://doi.org/10.1080/0020739X.2015.1075613

Shulman, L. S. (1986). Those who understand: Knowledge growth in teaching. Educational Researcher, 5(2), 4-14. https://doi.org/10.3102/0013189X015002004

Stupel, M., \& Ben-Chaim, D. (2013). One problem, multiple solutions: How multiple proofs can connect several areas of mathematics. The Far East Journal of Mathematical Education, 11(2), 129-161.

Stupel, M., Sigler, A., \& Oxman, V. (2017). Dynamic investigation of triangles inscribed in a circle, which tend to an equilateral triangle. The International Journal of Mathematical Education in Science and Technology (UK), 48(1), $149-161$. https://doi.org/10.1080/0020739X.2016.1206978

Yerushalmy, M., \& Chazan, D. (1993). Overcoming visual obstacles with the aid of the supposer. In J. L. Schwartz, M. Yerushalmy, \& B. Wilson (Eds.), The geometric supposer: What is it a case of? (pp. 25-56). Erlbaum. 